\title{
Configuration Model for Automating Work System Design
}

\author{
Muhamad Arfauz A. Rahman ${ }^{1}$, John P. T. Mo ${ }^{2}$ \\ ${ }^{1}$ Faculty of Manufacturing Engineering, Universiti Teknikal Malaysia Melaka, Hang Tuah Jaya, Malaysia; ${ }^{2}$ School of Aerospace \\ Mechanical and Manufacturing Engineering, Bundoora, Australia. \\ Email: arfauz@utem.edu.my
}

Received May $5^{\text {th }}, 2012$; revised June $4^{\text {th }}, 2012$; accepted July $2^{\text {nd }}, 2012$

\begin{abstract}
The design of an automation work system involves important choices concerning the type of system process as well as the condition of the process. These are based on the requirements from the user. This work provides the development of configuration model for automating the design of work system. The model consists of the extraction and execution process of user requirements. It begins with the identification of the requirement statement. Once identified, the statement is extracted and sorted accordingly into process type, number of item count and condition of the process. Currently, the model considers simple sorting and basic assembly process. The model continues to the selection of system action and system component. At the end of the work, the user requirements are transformed into a set of system model and eventually provide the desired system specification. At this stage, the model is represented in a symbolic flow process.
\end{abstract}

Keywords: Automation; Configuration; System Actions; System Components; User Requirements; Work System

\section{Introduction}

In configuring the automation work system, Mo et al. [1] believe that the goal is not about adapting one system to another, but rather to develop an automation work system from a task description independent of the other system, and subsequently assign components to achieve the specified function. Configuration of manufacturing systems is a strategic decision. However, many companies have lost their production capabilities every time they acquire a new system or modifying existing system. Regardless of the cause, companies have a challenging problem arise due to selecting new resources that fit their future needs better $[2,3]$. This phase is a very critical since each decision taken will directly affect the performance of the new system at this level and therefore its profitability in the future. Often, the information available at the early configuration stage is not detailed and is sometimes uncertain. According to Matta et al. [4] this is true especially when uncertainty of the market demand need to be considered during the configuration of the system. This is important since unexpected variations of the volumes required by the market, or the introduction of new products, can make the solution unsuitable to fulfill the market requests. At the same time, the decision must consider many system variables such as the process type, number of iteration and the process condition. To solve the problem, a simplified methodology that can deal with all the aspects described above is necessary.

\section{Configuration Phase}

To understand the configuration process, phases involve in the designing of work system must be understood and followed. The following Figure 1 shows the configuration and reconfiguration phases of work system.

The success of any automation work system configuration and reconfiguration will depend upon how well the system is executed at the beginning of the phase. The figure shows the generic configuration process that was concluded based on various methods on configuration and reconfiguration process include Monfared and Weston [5], Stoin and Frumusanu [6], Wiendahl et al. [7], Travaini et al. [8], and ElMaraghy et al. [9]. Variation in customer demands indicates changes in the market. Specific method on the acquisition of the user requirements and later transforming the information into system specifications has not been done. In line with the changes, Covanich and McFarlane [10] through their case study believe that an easy and simple engine is required to manipulate the requirement from the customers. Changes in market indicate changes in user requirements. Ferscha et al. [11] have agreed that a low flexibility of the system is amongst the challenges that limit the system's capability to adapt with new requirement. Therefore, new systems need to be set up. However setting up a new system is very costly. Often reconfigurable manufacturing system (RMS) the current system is manipulated to suit with the new requirement. 


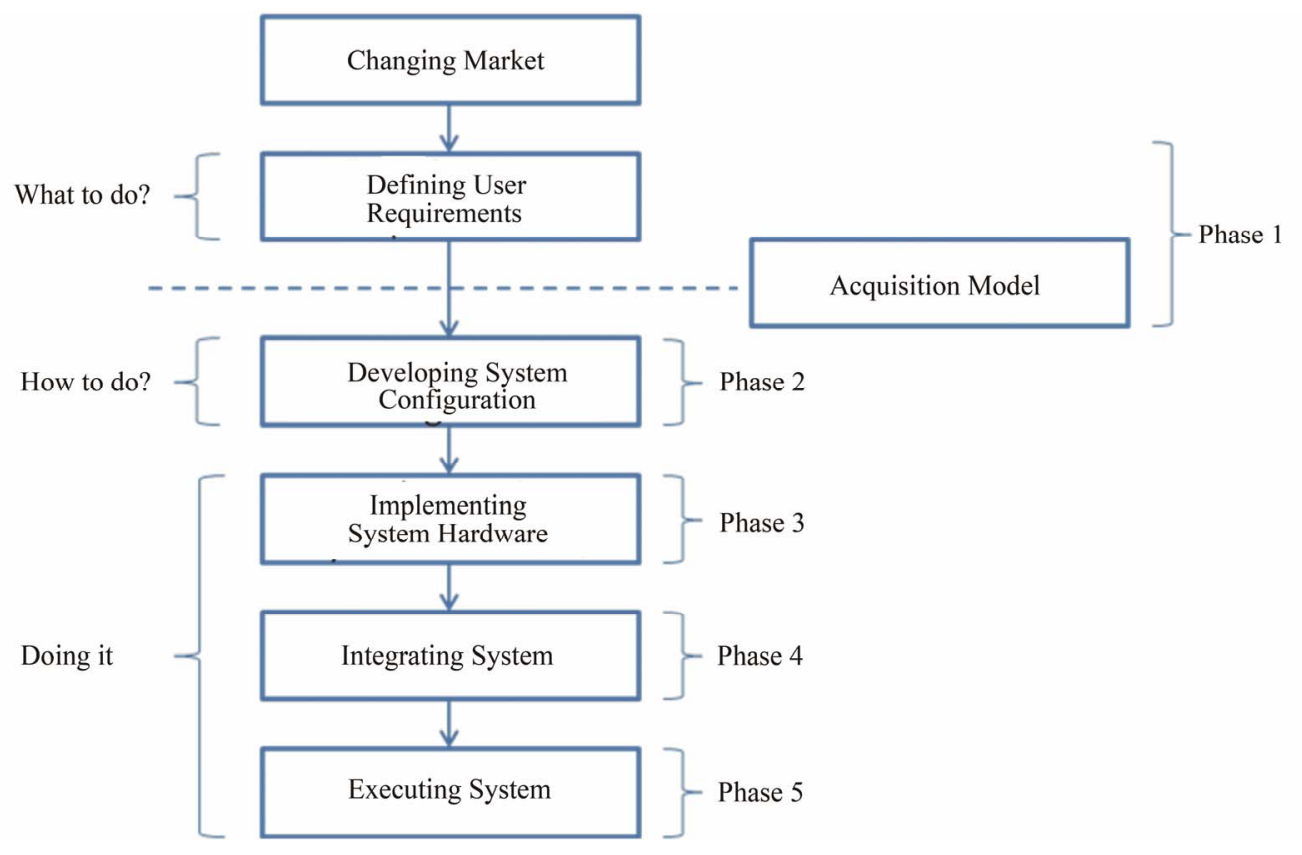

Figure 1. Work system configuration phases.

An appropriate system specification is an essential step leading to the successful implementation of automation work system configuration. Toni and Tonchia [12] had earlier discovered that the system needs to be configured and reconfigured accordingly from time to time in order to adapt with the new user requirements.

In specifying system specifications, few components need to be visualized. These include action of each process known as system actions as well as the corresponding components known as system component provided by Rahman and Mo [13]. Once the specification has been produced, the next process involves implementing the system in term of hardware. The implementation stage often requires manual step. At this stage, the research requires diverse concept not limited to initial configuration of a new automation work system but also to reconfigure the existing system. According to Mo et al. [1], in building an automation system, components required may be associated through physical or non physical specifications at different types. Due to various changing needs, addition or removal of physical components in the system will be severely affected, thus affecting the financial component as well. The first step to configure the system is to design the system accordingly.

The next process involves the integration of the hardware system with any software component. Various method for integrating the component have been introduced including through combined ontological representation of the low-level functionality at the high-level control layer by Lepuschitz et al. [14] and through Reconfigurable Manufacturing Execution Systems Architecture (RMESA) by Huang et al. [15]. This includes programmable logic controller or micro controller. The final stage of the phase will be the execution part.

Currently, the acquisition process shown in Figure 1 is conducted manually in which a group of system design engineer organized many discussions and meetings to understand the user requirements and specifications. However there is no effort to tackle the capturing of the requirements and transforming it into the system specifications using the mention method. This is essential because the system specification is scenario dependent in which the requirements will provide more precise information towards reconfiguration. Hence, without properly capture the requirements; the system may have not been designed correctly. It is obvious from the reviews that various methods on configuration and reconfiguration were created but there were no specific research conducted on capturing the requirements. Capturing the requirements or user requirements is essential steps to simplify the configuration and reconfiguration works as shown in Figure 1.

To act as fast as possible, a specific automated method to capture and manipulate the user requirements and later provide an optimum solution for the design of flexible and reconfigurable manufacturing automation system is essential to complement with the current effort. It is noted that the outcome of this work will undoubtedly provide highly flexible and easily platform to adapt with various manufacturing conditions with also less human involvement. This platform will not only cater for initial system design and development but also for system reconfiguration as well. 


\section{Focus Development}

In this work, the focus is on developing item in phase 1 and 2 of Figure 1. In order to come up with a suitable method, a specific model for extraction and configuration needs to be introduced. The actual theory of the model is briefly explained in this section. The initial work need to be initiated. The idea is to introduce the extraction process. The detail activity for this work is shown in the following Figure 2.

In Figure 2, the configuration process starts after the requirements are received from the customer, i.e. from the market. The process then continues analyzing the requirements and extracts the key elements from the input information. The outcomes of the requirements are passed to the configuration module which produces the proposed configuration for implementation.

\subsection{Requirements}

The critical task in the automated configuration system is recognition of user requirements. Most of the requirement information comes directly from the customer but there are other channels such as media and market intelligence sources that can be consolidated into some description for the system designer. In reality, these requirements are expressed in documents which are vague and often misleading. Therefore, many engineering design teams use the concept of quality function deployment (QFD) [16]. Jiang et al. [17] presented an overall review of QFD in the past 30 years. They adopted the "action research" approach interacting with product development groups and organisation, and proposed a model with 17 subsystems that linked system and product design to quality. Ocak [18] studied 2 competing companies using QFD method to provide a comprehensive, systematic approach to ensure customer requirements and expectations are met via applying improvements to design, production and management phases in manufacturing system design. The results of the QFD study could assist the companies to focus on specific issues.

Traditionally, QFD is used to capture the voice of the customer (i.e. requirements) and translates it into technical design requirements [19]. According to Mehrjerdi [20], the source of information for determining requirements come marketing surveys and case studies. More importantly, the requirements of the so-called unspoken customers could be captured by the "house of quality" (HoQ) [21]. The concept of HoQ originated from Toyota Motor Corporation [22]. The tool is composed of a set of matrices that represents the relationships between customer requirements (CRs) and technical characteristics (TCs). Once these relationships are quantified, a combination of different analysis and decision methods can be used to determine the outcome.

However, the QFD concept and HoQ methodologies have some drawbacks [23]. An inconsistent HoQ chart is one in which the information from the roof matrix is inconsistent with that from the relationship matrix. It is necessary to establish processes through which the consistency of information collected in HoQ and QFD is checked [24]. The system reconfiguration projects that this paper investigates certainly need information from the user to determine the best option for the manufacturing tasks. Capturing user requirements in the least restriction manner is essential to facilitate accuracy through the descriptions [25]. Hence, this research adopts a linquistic approach to capture user requirements from sentences.

Examples of user requirements are illustrated in the following sentences:

a) Sort 2 materials by weight;

b) Assemble 2 parts by inserting B on top of A;

c) Paint the 2 surface with 2 different colors;

d) Classify object according to 4 different colors;

e) 4 items need to be categorized according to height.

These requirements contain useful information for

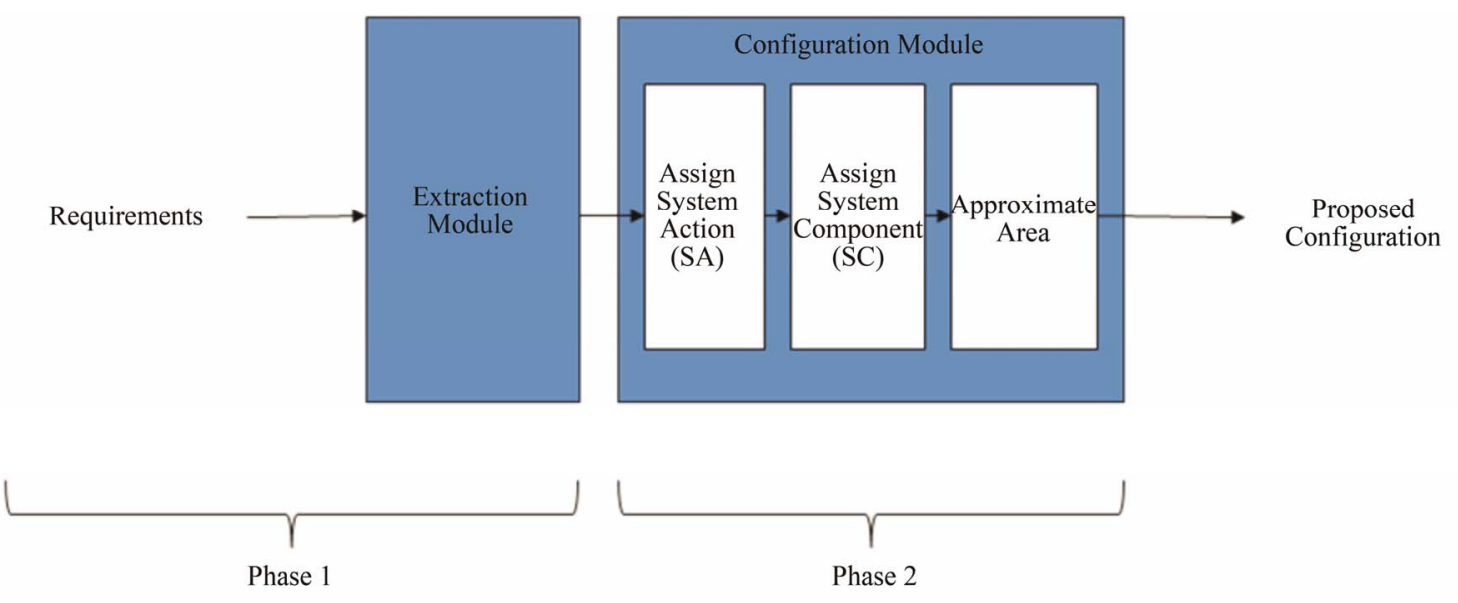

Figure 2. Extraction and configuration activity. 
system designer to configure a new system. According to Rahman and Mo [13], a basic user requirement can be divided into three main elements. There are type of process $(\mathrm{P})$, condition $(\mathrm{C})$ and number of iteration (I). According to Ratchev et al. [26], these elements will give basic information required to configure a system and are required to identify the general idea of the system to be designed. A simple method to differentiate between all the elements is described in the next section.

\subsection{Extraction Module}

To configure a system, user requirements need to be clearly identified and simplified. At the beginning of the process, an understandable set of user requirements is required, either from verbal description or by some documentation or statement, to formulate a conceptual model of what the system is supposed to do. The key in this process is the identification of user requirements in sentence and keywords, which have unique meanings. Later, the user requirement will be transformed into system specifications. These forms are well presented by Manesh [27].

From the examples in previous subsection, it is logical to divide the user requirements into the three elements $\mathrm{P}$, $\mathrm{I}$ and $\mathrm{C}$. The following describe examples of characteristics of the elements.

a) Possible Process Type (P):

Sort-1, 2, 3, $\cdots$, n product

Assemble-1, 2, 3, $\cdots$, n part

Hence, the main characteristic of $\mathrm{P}$ is based on keywords which are contained as verbs.

b) Possible Number of Item Count (I):

"n" number of product

"n" number of part
Hence, the main characteristics of $\mathrm{I}$ is integer numbers, starting from $1,2,3, \cdots, n$.

c) Possible Condition (C):

By weight, material, height

From side, top, bottom

Hence, the main characteristic of $\mathrm{C}$ is based on keywords, but they are adjective.

Now, the extraction process can be defined with the following rules:

For P, extract by a database of key verbs.

For I, look for numbers.

For $\mathrm{C}$, look for adjective etc. in the database.

In order for the configuration module to derive the result, the elements $\mathrm{P}, \mathrm{I}$ and $\mathrm{C}$ are required to be extracted from the user requirements. For example, using user requirement (a), the extraction logic can be shown in Figure 3.

Generalising, we can map any user requirement by the following relation:

$$
\{\mathrm{R}\} \rightarrow\{\mathrm{P}, \mathrm{I}, \mathrm{C}\}
$$

In our case,

$$
\begin{aligned}
& \mathrm{R}=\text { Sort } 2 \text { materials by weight } \\
& \mathrm{P}=\text { Sort } \\
& \mathrm{I}=2 \\
& \mathrm{C}=\text { by weight }
\end{aligned}
$$

Similarly, analysing user requirement (b) gives the following relation:

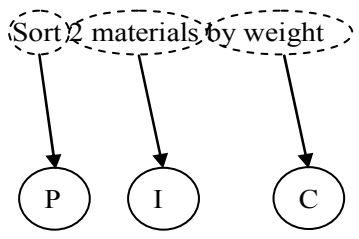

Figure 3. Extraction of user requirements.

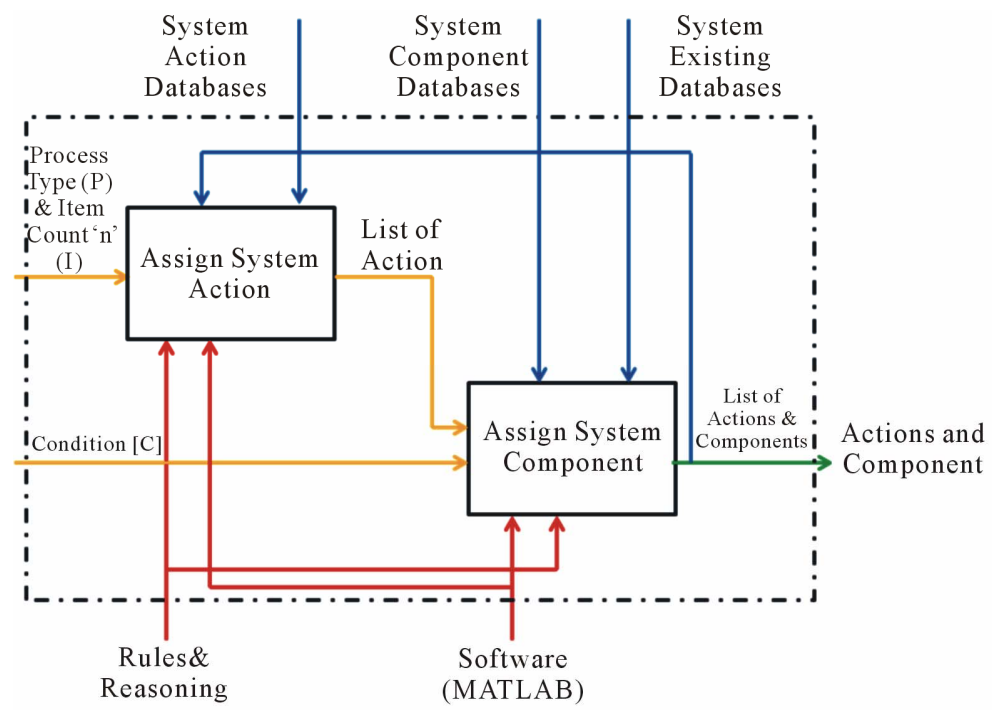

Figure 4. Generalized transformation system model. 


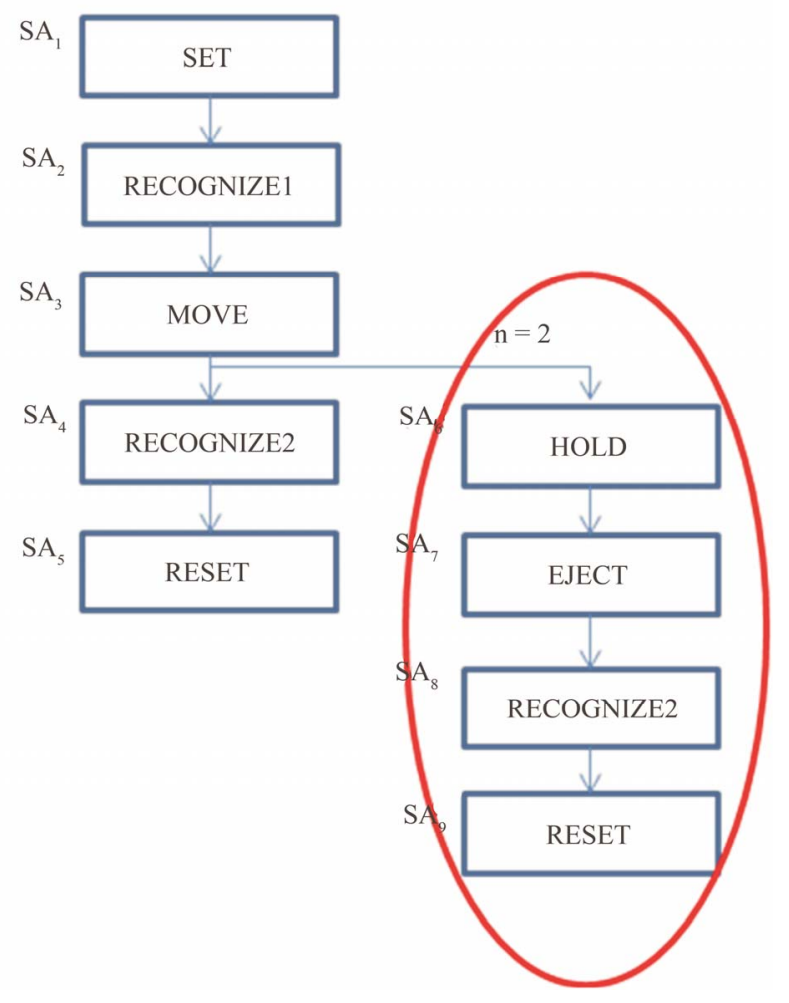

Figure 5. Sorting actions for two components.

\{Assemble 2 parts by inserting $B$ on top of $A$ \}

$\rightarrow\{$ Assemble, 2, by inserting $B$ on top of $A\}$.

\subsection{Configuration Module}

The generalized transformation of system model of this research part is shown in the following Figure 4.

In the figure, the beginning part shows the user requirements which can be categorized into three main parts. The figure clearly shows the following user requirements, $\mathrm{P}, \mathrm{I}$ and $\mathrm{C}$.

\subsubsection{System Action}

The first step to introduce a configuration model rose after a series or a combination of system action (SA) is created. In this case, the model can be initially shown in the following sequence:

$$
\mathrm{SA}_{1} \rightarrow \mathrm{SA}_{2} \rightarrow \mathrm{SA}_{3} \rightarrow \mathrm{SA}_{4} \rightarrow \cdots \rightarrow \mathrm{SA}_{n}
$$

The system action may consist of the following action SET, RESET, RECOGNIZE, MOVE, EJECT, HOLD. Selection and/or combination of the system action is based on the process type acquired from the user requirements commencing from 1 until $\mathrm{n}^{\text {th }}$ number. This $\mathrm{n}^{\text {th }}$ number indicates the total number of system action required to complete the process. It will depend on the number of item count (I) from the user requirement. The following Figure 5 shows a combination of system action for sorting process from a study conducted by Rahman and Mo [13]:

The combination shows sorting of 2 component of different weight. In this case $\mathrm{n}=2$ and the condition, $\mathrm{c}$ is weight. Further to the increment of the number of component to be sorted for $\mathrm{n}=3$ or more, another similar combination of system action was added as illustrated in Figure 6 for $n^{\text {th }}$.

From the combination, it shows a unique pattern that can be used to generalize the system action. Therefore, for "n" number of component to be sorted,

$$
\mathrm{N}_{\mathrm{SA}_{\mathrm{n}}}=5+(\mathrm{n}-1) 4
$$

For sorting case the value of $n \geq 2$, otherwise the process will not doing any sorting. In term of the sequence of the system action, the sorting process chooses alternative combination. The process will choose the system action combination accordingly upon receiving the information at the earlier recognition process at $\mathrm{SA}_{2}$. The process will be decided to proceed with $\mathrm{SA}_{4}$ or $\mathrm{SA}_{6}$ immediately after $\mathrm{SA}_{3}$.

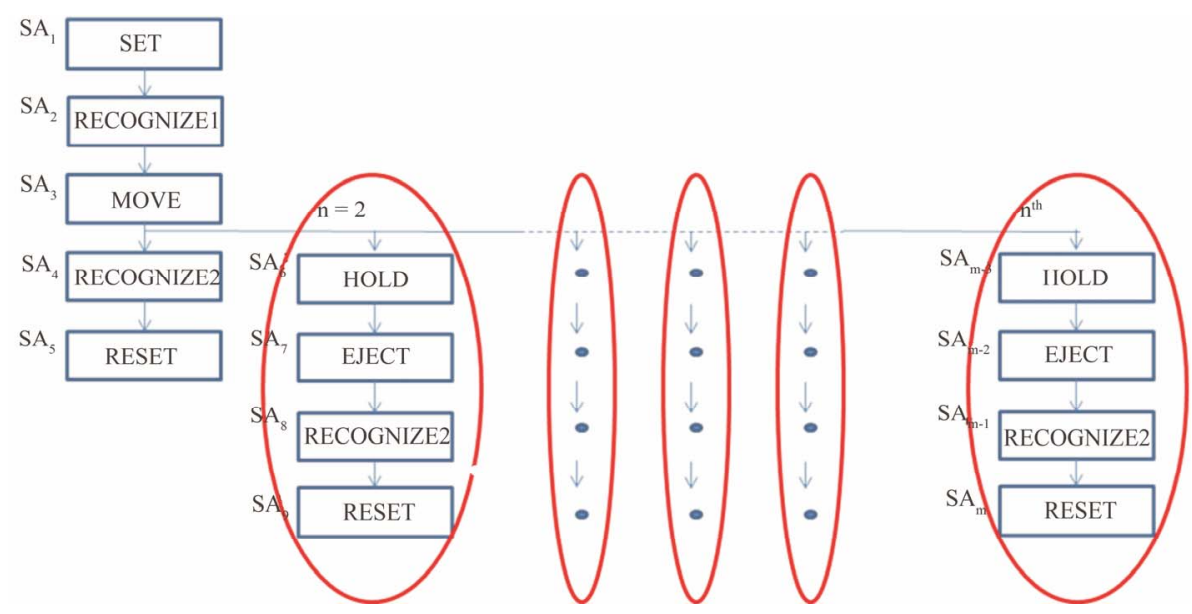

Figure 6. Sorting actions for five components. 


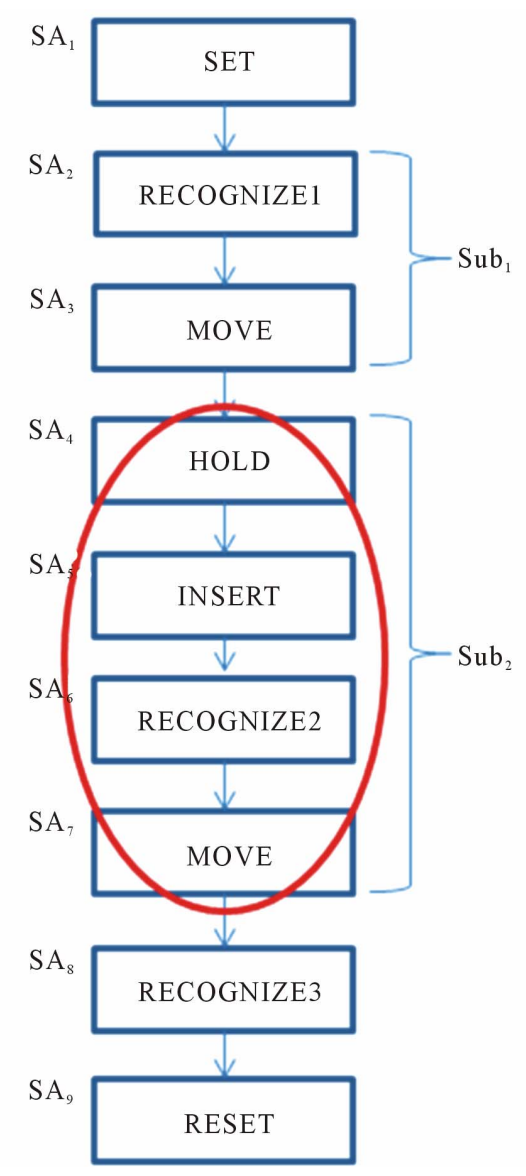

Figure 7. Assembly actions for two subassemblies.

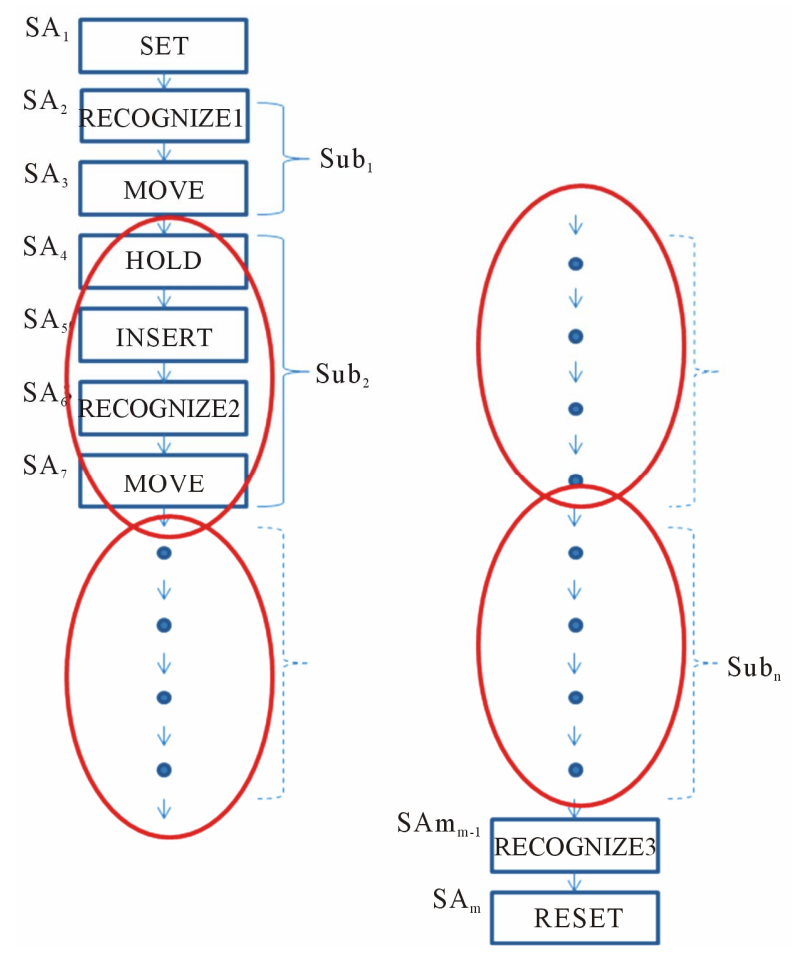

Figure 8. Assembly actions for five subassemblies.

$$
\text { Sort }_{\mathrm{SA}_{\mathrm{Sep}}}=3 \mathrm{SA}_{\text {SortBase1 }} \rightarrow\left\{\begin{array}{c}
2 \mathrm{SA}_{\text {SortBase2 }} \\
\text { or } \\
4 \mathrm{SA}_{\text {Alternative }}
\end{array}\right.
$$

In order to study the other type of processes, the following combination of system action for assembly can also be shown in Figure 7 as follows:

The combination shows assembly of two subassemblies together for $n=2$ case. For assembly of three subassemblies of $\mathrm{n}=3$ or more, combination of four system action, will occurs. Finally, Figure 8 shows combination for $\mathrm{n}^{\text {th }}$.

Again, the combination shows a unique pattern than can be generalized for indicating the total number of system action required for this assembly process:

$$
\mathrm{N}_{\mathrm{SA}_{\mathrm{n}}}=5+(\mathrm{n}-1) 4
$$

The value of $\mathrm{n}$ for assembly process is $\geq 2$, otherwise the process will not do assembling task. In term of the sequence of the system action, the assembly process chooses direct combination. The process will add the system action combination accordingly upon receiving the information at the earlier recognition process at $\mathrm{SA}_{2}$. The process will add numbers of subassemblies accordingly.

$$
\text { AssySA }_{\text {Seq }}=3 \mathrm{SA}_{\text {AssyBase1 }} \rightarrow(\mathrm{n}-1) 4 \mathrm{SA} \rightarrow 2 \mathrm{SA}_{\text {AssyBase2 }}
$$

Each system action will indicate a need for certain type of component. In the next section system component (SC) is introduced to the current combination which will further derive the model.

\subsubsection{System Component}

Given a single combination of system action, each system action will react and correspond to a specific system component from the system component repository. In this case, the total number of system component is similar to the total number of system action.

$$
\begin{aligned}
& \mathrm{SA}_{1} \rightarrow \mathrm{SA}_{2} \rightarrow \mathrm{SA}_{3} \rightarrow \mathrm{SA}_{4} \rightarrow \cdots \rightarrow \mathrm{SA} \\
& \mathrm{SC}_{1} \rightarrow \mathrm{SC}_{2} \rightarrow \mathrm{SC}_{3} \rightarrow \mathrm{SC}_{4} \rightarrow \cdots \rightarrow \mathrm{SC}_{\mathrm{n}}
\end{aligned}
$$

At this stage, list of component are required in order to suit with the desired system component as well as corresponding system action. Since the expected outcome of the manufacturing system may differ from one to another, extensive lists are required. A set of components will be created which will store the database and will be known as system component repository. This repository contains numbers of components needed for setting up various types of system. The repository will provide heaps of data regarding various components required in the processing level of the proposed configuration work. The following Table 1 shows an example of the developed 
Table 1. Repository system for system component with corresponding system action.

\begin{tabular}{lll}
\hline SA Level & SC Level (Generic) & SC Level (Specific) \\
\hline EJECT & CYLINDER & $\mathrm{CL}_{1}, \mathrm{CL}_{2}, \mathrm{CL}_{3}, \cdots, \mathrm{CL}_{\mathrm{n}}$ \\
HOLD & Others & \\
& CYLINDER & $\mathrm{CL}_{1}, \mathrm{CL}_{2}, \mathrm{CL}_{3}, \cdots, \mathrm{CL}_{\mathrm{n}}$ \\
RECOGNIZE & Others & \\
& SENSOR & $\mathrm{SN}_{1}, \mathrm{SN}_{2}, \mathrm{SN}_{3}, \cdots, \mathrm{SN}_{\mathrm{n}}$ \\
MOVE & Others & \\
& CONVEYOR & $\mathrm{CV}_{1}, \mathrm{CV}_{2}, \mathrm{CV}_{3}, \cdots, \mathrm{CV}_{\mathrm{n}}$ \\
& TURN TABLE & $\mathrm{TT}_{1}, \mathrm{TT}_{2}, \mathrm{TT}_{3}, \cdots, \mathrm{TT}_{\mathrm{n}}$ \\
& LIFTING MECHANISM & $\mathrm{LM}_{1}, \mathrm{LM}_{2}, \mathrm{LM}_{3}, \cdots, \mathrm{LM}_{\mathrm{n}}$ \\
SLIDE & Others & \\
& SLIDER & $\mathrm{SL}_{1}, \mathrm{SL}_{2}, \mathrm{SL}_{3}, \cdots, \mathrm{SL}_{\mathrm{n}}$ \\
MEMORIZE & Others & \\
& PLC & $\mathrm{PLC}_{1}, \mathrm{PLC}_{2}, \mathrm{PLC}_{3}, \cdots, \mathrm{PLC}_{\mathrm{n}}$ \\
\hline
\end{tabular}

repository system for system component with corresponding system action.

Selection of the system component is base on individual system action acquired in the prior stage. An easy relationship between System Model (SM), System Action (SA) and System Component (SC) can be concluded. In every single system model, there can be more than one similar system action (a repetition of system action). The following symbolic relationship can be used to illustrate the process.

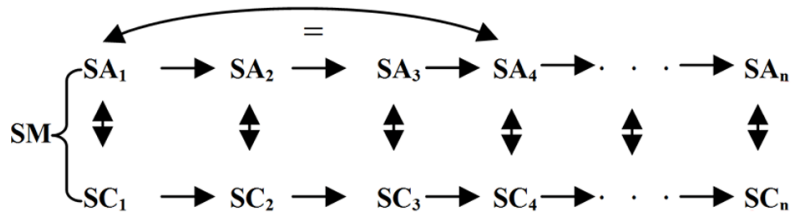

While in every repetition of system action in each final system model, the corresponding system component can be of a similar or different component.

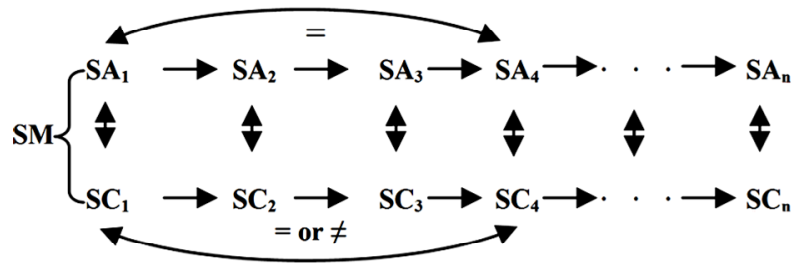

In a nutshell, the model which consist of combination of system action (SA) with corresponding system components (SC) can be rewritten in a function form of

$$
\mathrm{SM}=\{\mathrm{SA}, \mathrm{SC}\}
$$

\subsubsection{System Actions and Components Selection}

Selection/combination of the system action is based on the process type acquired from the user/system require- ments. On top of that, the selection of the component is also based on the condition (c) extracted from the user requirement. The following Figure 9 shows an example of the selection of system components with corresponding system actions.

For sorting process, Table 2 is an example of conditions, c (see Table 2).

In our case, the condition chosen is weight and the following assigned identification of system component in corresponds to the system action is shown in Table $\mathbf{3}$ (see Table 3).

For Assembly process, Table 4 shows few example of assembly condition, c (see Table 4).

In our case, the condition is inserting part B onto part $\mathrm{A}$ and the following assigned identification of system component in corresponds to the system action is shown in Table 5 (see Table 5).

Selection and/or combination of the system models are based on the number of iteration acquired from the user requirements commencing from 1 until $n^{\text {th }}$ number. This $\mathrm{n}^{\text {th }}$ number will therefore depend on the iteration of the process in the system.

\section{Implementing System Hardware}

\subsection{Space Utilization}

The next steps towards the implementation stages are to finalize the system actions and system components selection from the database. Once the components are selected, the approximate size of the system can be obtained for initial prediction of the space required for lying down the system. Table 6 shows the relationship to select the suitable components for each the actions for sorting.

On top of the listed components, accessories to run the 


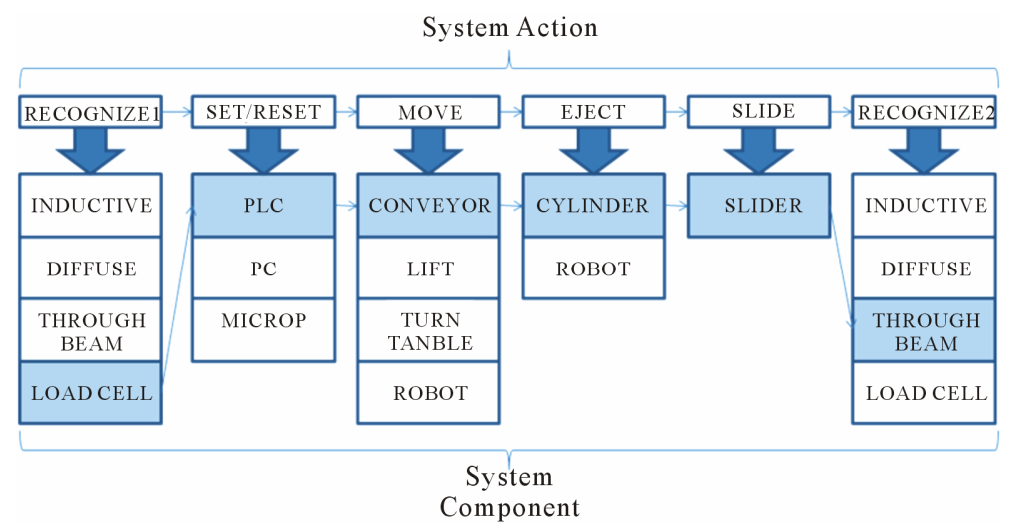

Figure 9. Selection of system components with corresponding system actions for sorting process.

Table 2. Example of sorting condition.

\begin{tabular}{cc}
\hline CONDITION & IDENTIFICATION \\
\hline Weight & 1 \\
Colour & 2 \\
Height & 3 \\
Shape & 4 \\
\hline
\end{tabular}

Table 1. Identification assignment for weight sorting.

\begin{tabular}{ccccc}
\hline CONDITION & IDENTIFICATION & SYSTEM ACTION & IDENTIFICATION & SYSTEM COMPONENT \\
\hline \multirow{6}{*}{ Weight } & SET/RESET & 0.1 & PLC \\
& \multirow{2}{*}{1} & RECOGNIZE1 & 1.1 & LOAD CELL SENSOR \\
& & RECOGNIZE2 & 1.2 & THROUGH BEAM \\
& MOVE & 2.1 & CONVEYOR \\
& HOLD & 3.1 & CYLINDER1 \\
& EJECT & 3.2 & CYLINDER2 \\
\hline
\end{tabular}

Table 2. Example of assembly condition.

\begin{tabular}{cc}
\hline CONDITION & IDENTIFICATION \\
\hline Insert from top & 1 \\
Insert from side & 2 \\
Insert from bottom & 3 \\
\hline
\end{tabular}

Table 3. Identification assignment for assembly by inserting subassembly from top.

\begin{tabular}{|c|c|c|c|c|}
\hline CONDITION & IDENTIFICATION & SYSTEM ACTION & IDENTIFICATION & SYSTEM COMPONENT \\
\hline \multirow{7}{*}{ Insert from top } & \multirow{7}{*}{1} & SET/RESET & 0.1 & PLC \\
\hline & & RECOGNIZE1 & 1.1 & PROXIMITY SENSOR \\
\hline & & RECOGNIZE2 & 1.2 & LIMIT SWITCH \\
\hline & & RECOGNIZE3 & 1.3 & THROUGH BEAM \\
\hline & & MOVE & 2.1 & CONVEYOR \\
\hline & & HOLD & 3.1 & CYLINDER \\
\hline & & INSERT & 4.1 & FEEDER \\
\hline
\end{tabular}


system may be required but not included in this discussion. From the individual space information, the total required space for the complete system can be calculated as follow:

$$
\begin{aligned}
& \text { System space utilization }=\mathrm{SU} \\
& =\sum \mathrm{A}_{i}=\mathrm{A}_{1}+2 \mathrm{~A}_{2}+\mathrm{A}_{3}+\mathrm{A}_{4}+\mathrm{A}_{5}+\mathrm{A}_{6}
\end{aligned}
$$

The approximation of system space utilization layout for the configured sorting system in this work is shown in Figure 10.

The next Table 7 shows the component selection for assembly process.
Similar to sorting process, other accessories to run the system may be required but not included in this discussion. From the individual space information, the total required space for the complete system can be calculated as follow:

$$
\begin{aligned}
& \text { System space utilization }=\mathrm{SU} \\
& =\sum \mathrm{A}_{i}=\mathrm{A}_{1}+\mathrm{A}_{2}+\mathrm{A}_{3}+\mathrm{A}_{4}+\mathrm{A}_{5}+\mathrm{A}_{6}
\end{aligned}
$$

The approximation of system space utilization layout for the configured assembly system in this work is shown in Figure 11.

Table 4. Components selection for the configured sorting process.

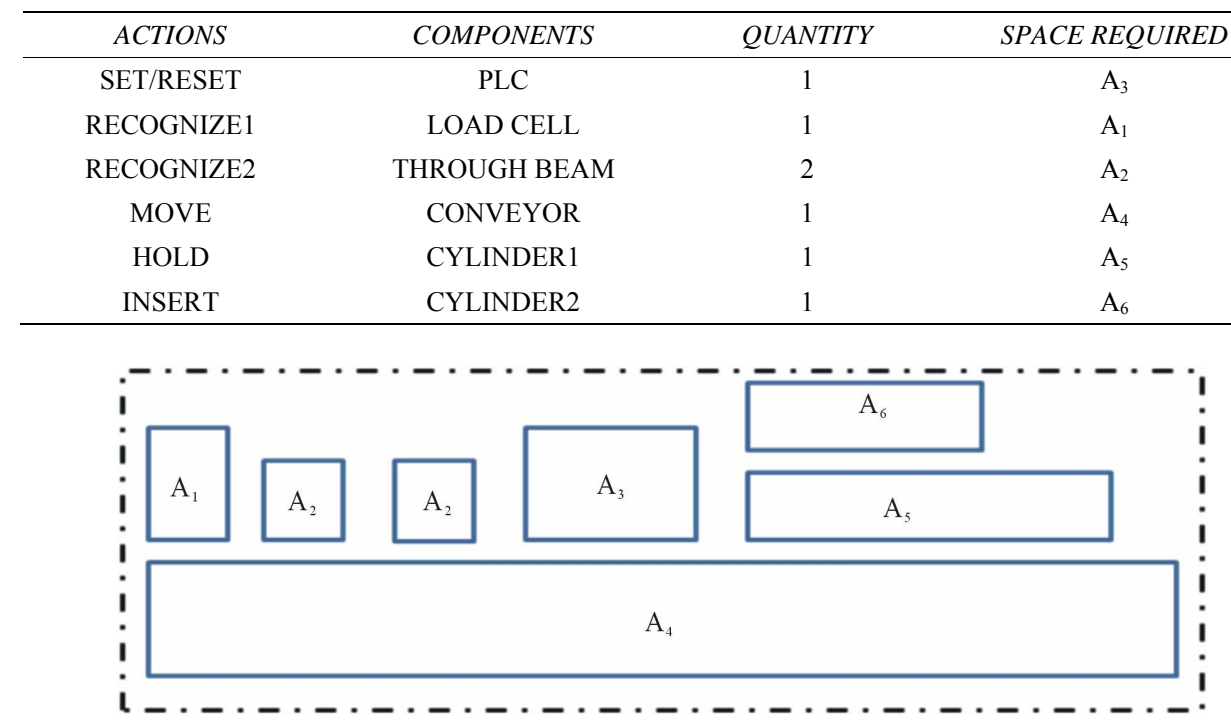

Figure 10. Space approximation for the configured sorting system.

Table 7. Components selection for the configured assembly process.

\begin{tabular}{llll}
\hline ACTIONS & COMPONENTS & QUANTITY & SPACE REQUIRED \\
\hline SET/RESET & PLC & 1 & $\mathrm{~A}_{3}$ \\
RECOGNIZE1 & PROXIMITY SENSOR & 1 & $\mathrm{~A}_{1}$ \\
RECOGNIZE2 & LIMIT SWITCH & 1 & $\mathrm{~A}_{2}$ \\
RECOGNIZE3 & THROUGH BEAM & 1 & $\mathrm{~A}_{4}$ \\
MOVE & CONVEYOR & 1 & $\mathrm{~A}_{5}$ \\
HOLD & CYLINDER & 1 & $\mathrm{~A}_{6}$ \\
INSERT & FEEDER & 1 & $\mathrm{~A}_{7}$ \\
\hline
\end{tabular}

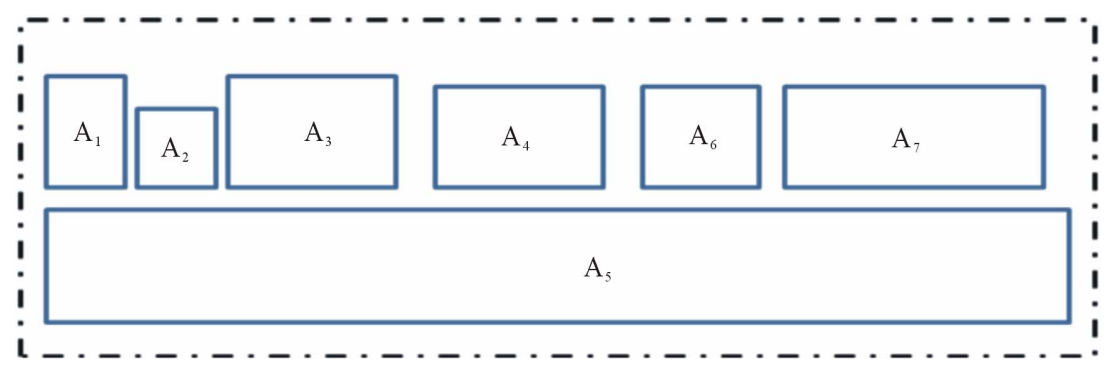

Figure 11. Space approximation for the configured assembly system. 
The layout is not a final layout but is more on the sizing of the proposed new configured system. At this stage it does not indicate specific orientation of the system. However the information is useful during layout orientation stage. The information gathered from this section will give valuable information in term of system space utilization.

\subsection{Proposal Mode: Implementation}

Once the system action and system components are available, the work system layout needs to be developed. In term of facilitating the layout of the system, various methods can be considered for automating the process. These includes genetic algorithm by Kar Yan [28], Peters [29] and other method suggested by Robin S. [30]. However, at this stage, the process is done manually by taking into consideration all information from the system model. The process will closely follow the information from the approximation of space required for necessary component. The initiation of the hardware implementation has been taken place using the modular automation system. This implementation was resulted from propose system model and space utilization study conducted for simple sorting process which can be seen in the following Figure 12.
The process involves laying out the components manually base on the system action and system component flow. Starting with the initial layout in Figure 11, the layout has gone through several iteration and adjustments at the final implementation stage. The next Figure 13 shows the orientation for the manual process.

The outcome of the study was implemented using the proposed model. An example of automation work system development for sorting process for two boxes of different weight is shown in Figure 14.

The implemented system operates using conveyor as the transfer system. Once the product is placed on the weighing station, the conveyor will transfer the product from the current spot until it reaches the decision area. At the decision area, the pneumatic cylinder will either push the product onto the first slider or let the product through to the second slider. This decision making process is done by the Programmable Logic Controller (PLC).

\section{Conclusion}

At this stage, the initial model to extract and manipulate the user requirements has been developed. The outcome of this work is the division of user requirements into process type, item count for the process and condition of process. The outcome will later provide with the general

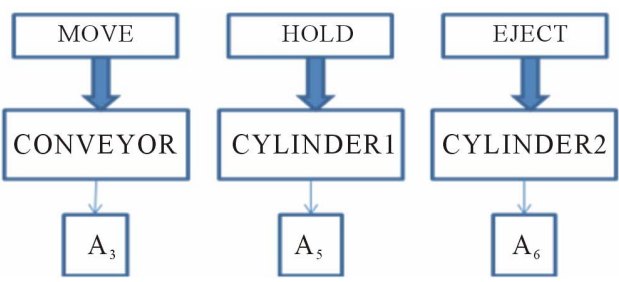

Figure 12. Implementation of component based on the system actions and system components.

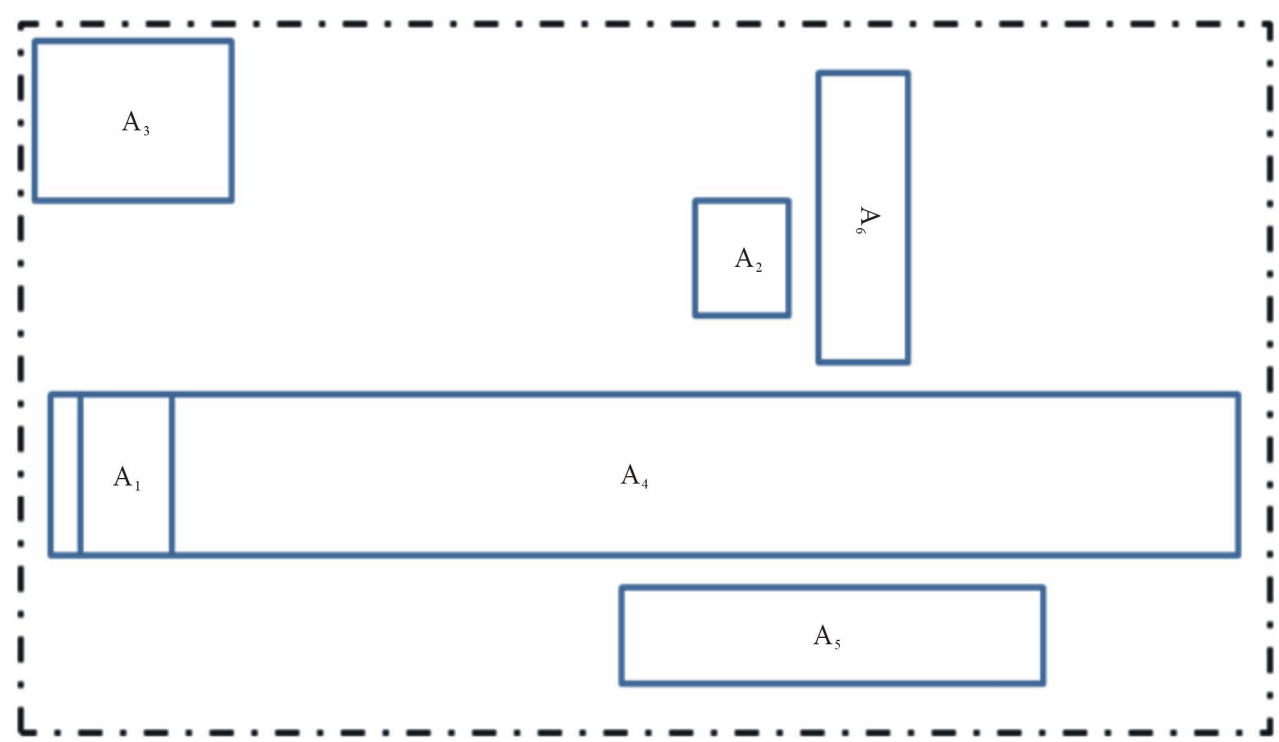

Figure 13. Orientation of the layout. 


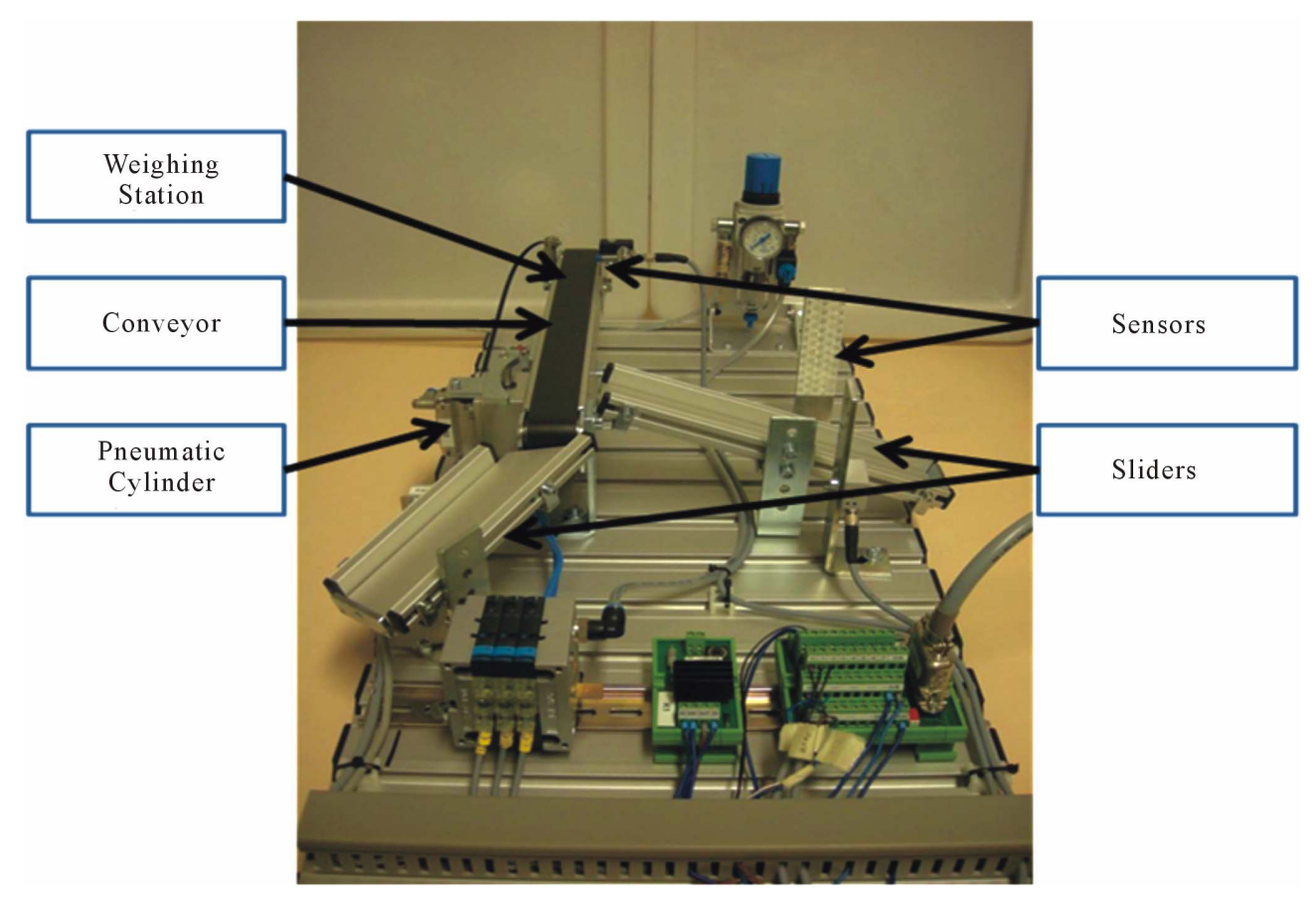

Figure 14. Hardware implementation for automation work system.

idea for laying out the system. This work proved that the common instructions, in this case the user requirements, can be generalized in configuring automation work system structure. In the future, this research work will benefit the industry through reducing human involvement while trying to optimize the current system and at the same time minimizing the risk of future investment in simple sorting and assembly. More work is currently underway to improvise the model to be used for both configuring and reconfiguring various complex type of system.

\section{Acknowledgements}

The present works was raised from the collaborative partnership between RMIT University, Australia and SAGE Didactic, Australia an established automation education facility supporting multi-level learning requirements. The researcher was financially supported by the Universiti Teknikal Malaysia Melaka (UTeM), Malaysia and Ministry of Higher Education (MOHE) Malaysia.

\section{REFERENCES}

[1] J. P. T. Mo, P. Dawson and M. A. A. Rahman, "Active Learning Approach in Developing Engineering Design Skill through Open Ended System Specification," 20th Australasian Association for Engineering Education Conference, Adelaide, 6-9 December 2009, pp. 61-66.

[2] H. ElMaraghy, et al., "Managing Variations in Products, Processes and Manufacturing Systems," CIRP AnnalsManufacturing Technology, Vol. 58, No. 1, 2009, pp. 441-446.
[3] U. Karmarkar and S. Kekre, "Manufacturing Configuration, Capacity and Mix Decisions Considering Operational Costs," Journal of Manufacturing Systems, Vol. 6, No. 4, 1987, pp. 315-324. doi:10.1016/0278-6125(87)90007-0

[4] A. Matta, et al., "An Integrated Approach for the Configuration of Automated Manufacturing Systems," Robotics and Computer-Integrated Manufacturing, Vol. 17, No. 1-2, 2001, pp. 19-26. doi:10.1016/S0736-5845(00)00033-8

[5] R. P. Monfared and R. H. Weston, "A Method to Develop Semi-Generic Information Models of Change-Capable Cell Control Systems," Computers in Industry, Vol. 41, No. 3, 2000, pp. 279-294. doi:10.1016/S0166-3615(99)00050-0

[6] C. Stoian and G. Frumusanu, "Reconfigurable Manufacturing Systems Design Principles," The Annals Dunarea de Jos of Galati, Fascicle V, Technolologies in Mecanical Engineering, Vol. 2007, No. 1, pp. 62-65.

[7] H. P. Wiendahl, et al., "Changeable ManufacturingClassification, Design and Operation," CIRP Annals - Manufacturing Technology, Vol. 56, No. 2, 2007, pp. 783809.

[8] E. Travaini, et al., "Methodological Approach and Reconfiguration Tool for Assembly Systems," CIRP AnnalsManufacturing Technology, Vol. 51, No. 1, 2002, pp. 913.

[9] H. A. ElMaraghy, O. Kuzgunkaya and R. J. Urbanic, "Manufacturing Systems Configuration Complexity," CIRP Annals-Manufacturing Technology, Vol. 54. No. 1, 2005, pp. 445-450.

[10] W. Covanich and D. McFarlane, "Assessing Ease of Reconfiguration of Conventional and Holonic Manufactur- 
ing Systems: Approach and Case Study," Engineering Applications of Artificial Intelligence, Vol. 22, No. 7, 2009, pp. 1015-1024. doi:10.1016/j.engappai.2009.01.001

[11] A. Ferscha, et al., "Building Flexible Manufacturing Systems Based on Peer-Its," EURASIP Journal on Embedded Systems, Vol. 2008, 2008. doi:10.1155/2008/267560

[12] A. D. Toni and S. Tonchia, "Manufacturing Fexibility: A Literature Review," International Journal of Production Research, Vol. 36, No. 6, 1998, pp. 1587-1617. doi:10.1080/002075498193183

[13] M. A. A. Rahman and J. P. T. Mo, "Development of Theoretical Reconfiguration Structure for Manufacturing Automation Systems," International Journal of Agile Systems and Management, Vol. 5, No. 2, 2012, pp. 132-150.

[14] W. Lepuschitz, et al., "Toward Self-Reconfiguration of Manufacturing Systems Using Automation Agents," IEEE Transactions on Systems, Man, and Cybernetics, Part C: Applications and Reviews, Vol. 41, No. 1, 2011, pp. 52-69.

[15] Y. Huang, et al., "Manufacturing Execution System Architecture Supporting Cross-Grain Reconfiguration," Jisuanji Jicheng Zhizao Xitong/Computer Integrated Manufacturing Systems, Vol. 17, No. 4, 2011, pp. 747-759.

[16] N. Fuller, "The House of Quality," Supply Management, Vol. 3, No. 3, 1998, p. 44.

[17] J.-C. Jiang, M.-L. Shiu and M.-H. Tu, "Quality Function Deployment (QFD) Technology Designed for Contract Manufacturing," TQM Journal, Vol. 19, No. 4, 2007, p. 291. doi:10.1108/09544780710756205

[18] Z. Ocak, "Applying Quality Function Deployment in the Manufacturing Industry: A Review \& Case Study in Production," The Business Review, Vol. 9, No. 2, 2008, p. 4.

[19] R. K. Singh, C. C. Elrod and E. A. Cudney, "Comparative Analysis of Quality Function Deployment Methodologies: A Case Study Analysis," The Quality Management Journal, Vol. 19, No. 1, 2012, p. 7.

[20] Y. Z. Mehrjerdi, “Applications and Extensions of Quality Function Deployment," Assembly Automation, Vol. 30, No. 4, 2010, p. 388. doi:10.1108/01445151011075843

[21] R. Mahanti, "The Application of Quality Function De- ployment to User Interface Design," The Quality Management Journal, Vol. 16, No. 1, 2009, p. 29.

[22] C.-H. Liu, "A Group Decision-Making Method with Fuzzy Set Theory and Genetic Algorithms in Quality Function Deployment," Quality and Quantity, Vol. 44, No. 6, 2010, p. 1175. doi:10.1007/s11135-009-9304-1

[23] A. Olewnik and L. Kemper, "Limitations of the House of Quality to Provide Quantitative Design Information," The International Journal of Quality \& Reliability Management, Vol. 25, No. 2, 2008, p. 125. doi:10.1108/02656710810846916

[24] J.-S. Shin, K.-J. Kim and M. J. Chandra, "Consistency Check of a House of Quality Chart," The International Journal of Quality \& Reliability Management, Vol. 19, No. 4, 2002, p. 471. doi:10.1108/02656710210421535

[25] S. Ratchev, H. Hirani and M. Bonney, "Knowledge Based Formation of Re-Configurable Assembly Cells," Journal of Intelligent Manufacturing, Vol. 18, No. 3, 2007, pp. 401409. doi:10.1007/s10845-007-0031-y

[26] H. F. Manesh, D. Schaefer and M. Hashemipour, "Information Requirements Analysis for Holonic Manufacturing Systems in a Virtual Environment," The International Journal of Advanced Manufacturing Technology, Vol. 53, No. 1-4, 2011, pp. 385-398. doi:10.1007/s00170-010-2822-0

[27] T. K. Yan, "Genetic Algorithms, Function Optimization, and Facility Layout Design," European Journal of Operational Research, Vol. 63, No. 2, 1992, pp. 322-346. doi:10.1016/0377-2217(92)90034-7

[28] B. A. Peters and M. Rajasekharan, "A Genetic Algorithm for Determining Facility Design and Configuration of Single-Stage Flexible Electronic Assembly Systems," Journal of Manufacturing Systems, Vol. 15, No. 5, 1996, pp. 316-324. doi:10.1016/0278-6125(96)84194-X

[29] S. L. Robin, "Automated Facilities Layout: Past, Present and Future," Automation in Construction, Vol. 9, No. 2, 2000, pp. 197-215. doi:10.1016/S0926-5805(99)00005-9

[30] S. L. Robin, "Automated Facilities Layout: Past, Present and Future," Automation in Construction. Vol. 9, No. 2, 2000, pp. 197-215. 